(2) Open Access Full Text Article

REVIEW

\title{
Scavenger receptor class B member I protein: hepatic regulation and its effects on lipids, reverse cholesterol transport, and atherosclerosis
}

This article was published in the following Dove Press journal:

Hepatic Medicine: Evidence and Research

7 April 201 I

Number of times this article has been viewed

\author{
Anthony $\mathrm{P}$ Kent \\ Ioannis M Stylianou \\ Department of Medicine and \\ Institute for Translational Medicine \\ and Therapeutics, University of \\ Pennsylvania School of Medicine, \\ Philadelphia, PA, USA
}

\begin{abstract}
Scavenger receptor class B member 1 (SR-BI, also known as $S C A R B 1$ ) is the primary receptor for the selective uptake of cholesterol from high-density lipoprotein (HDL). SR-BI is present in several key tissues; however, its presence and function in the liver is deemed the most relevant for protection against atherosclerosis. Cholesterol is transferred from HDL via SR-BI to the liver, which ultimately results in the excretion of cholesterol via bile and feces in what is known as the reverse cholesterol transport pathway. Much of our knowledge of SR-BI hepatic function and regulation is derived from mouse models and in vitro characterization. Multiple independent regulatory mechanisms of SR-BI have been discovered that operate at the transcriptional and post-transcriptional levels. In this review we summarize the critical discoveries relating to hepatic SR-BI cholesterol metabolism, atherosclerosis, and regulation of SR-BI, as well as alternative functions that may indirectly affect atherosclerosis.
\end{abstract}

Keywords: SR-BI, SCARB1, lipids, atherosclerosis, CAD, mouse models

\section{Function and structure of SR-BI and other class B scavenger receptors}

Scavenger receptor class B member 1 (SR-BI, gene name SCARB1) belongs to the CD36 superfamily of membrane-bound, cell-surface glycoproteins, which include mammalian scavenger receptor CD36 and the lysosomal membrane protein 2 (gene name SCARB2, formerly LIMPII). ${ }^{1}$ These receptors can bind to modified forms of low-density lipoprotein (LDL) as well as native high-density lipoprotein (HDL) and very low density lipoprotein (VLDL)., ${ }^{2,3}$ However, SR-BI is distinguished from other class B scavengers by its high affinity to facilitating selective cholesterol uptake from HDL, without the internationalization and degradation of the apolipoprotein-AI (APOA1)-containing whole particle. ${ }^{2}$ There are several common structural features shared among this family of proteins. These include membrane-associated hydrophobic regions near the $\mathrm{N}$ - and $\mathrm{C}$-termini, a large extracellular loop comprising the portion of the peptide sequence between the two membrane-bound end regions, and several sites of N-linked glycosylation. ${ }^{4}$

SR-BI and CD36 share considerable sequence homology throughout much of their extracellular loop, with several conserved cysteine and asparagine residues, as well as canonical sites of fatty acylation and N-linked glycosylation. Interestingly, SR-BI and CD36 bear little sequence homology in their transmembrane and N- and C-terminal membrane-associated domains. ${ }^{5} \mathrm{SR}-\mathrm{BI}$ is considered the HDL cholesteryl ester (HDL-CE) selective uptake receptor, CD36 is often ignored or described as not having HDL-CE selective uptake activity. While it has been known for some time 
that CD36 knockout $(\mathrm{KO})\left(\mathrm{Cd} 36^{-/-}\right)$mice exhibit increased plasma HDL, and recently HDL-CE selective uptake activity was shown to be impaired in $\mathrm{Cd} 36^{-/-}$mice compared to control mice. ${ }^{6}$ In vitro studies comparing CD36 and SR-BI showed that both bound to HDL and both mediated HDL-CE selective uptake; however, CD36 mediates selective uptake at a slower rate than SR-BI. 5,7,8 CD36 and SR-BI also have similar binding capabilities to a variety of particles and ligands other than HDL, including acetylated LDL and oxidized LDL (oxLDL), although CD36 is considerably better at binding and internalizing oxLDL than SR-BI. ${ }^{9}$ CD36 can also mediate binding and uptake of carbamylated LDL in endothelial cells, although the impact in the liver and that of SR-BI have not been reported, ${ }^{10}$ and CD36 has significant fatty acid translocase activity, which may be the primary metabolic function of CD36. ${ }^{11}$

The primary structure of murine SR-BI is a 509 amino acid sequence, with a predicted mass of $\sim 57 \mathrm{kDa} \cdot{ }^{12,13}$ However, Western blot analysis of tissues and cultured cells indicates that SR-BI is an 80-84 kDa protein due to significant post-translational processing. ${ }^{12}$ Site-directed mutagenesis experiments have confirmed that mouse SR-BI is fatty acylated at two cysteine residues in the cytoplasmic domain of the C-terminus at the junction of the transmembrane region (Cys462 and Cys470). ${ }^{5}$ In addition, SR-BI undergoes homooligomerization to form dimers and tetramers ${ }^{14-18}$ that are dependent on C-to-C-transmembrane and/or C-C-terminal interactions (Figure 1). ${ }^{14} \mathrm{It}$ is likely that these oligomers form a hydrophobic channel whereby water is excluded ${ }^{15,19,20}$ and HDL-CE molecules move toward the plasma membrane, which has a low concentration of CE. ${ }^{19}$

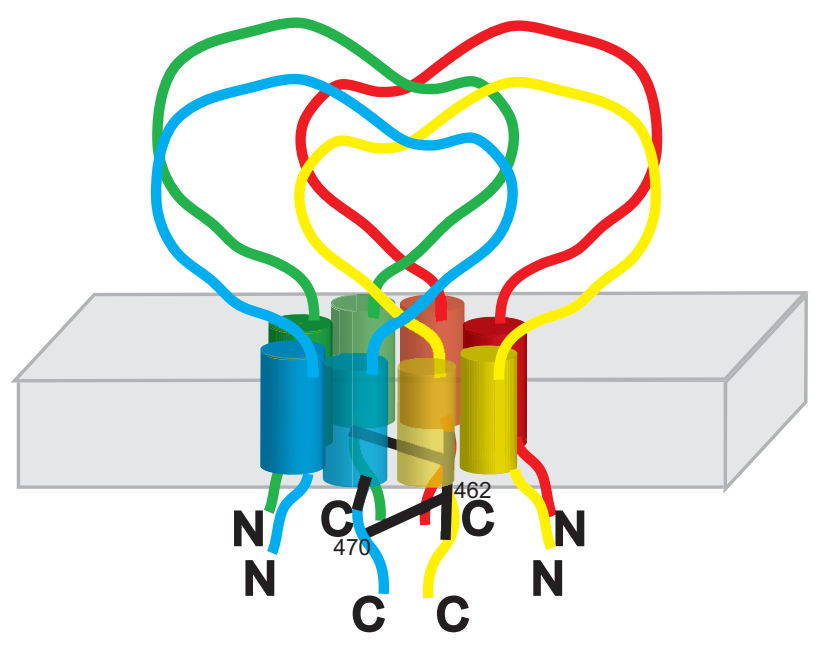

Figure I Hyphothetical structure of scavenger receptor class B member I membrane-bound tetramer with potential cysteine-to-cysteine (Cys462 and Cys470) interactions interconnecting the four C-termini.
There are four known alternatively coding SR-BI splice variants. In mouse liver, SR-BI and SR-BI.2 (also described as SR-BII) are the most common. There is no detailed characterization of the other two variants described in genome databases. SR-BI.2 differs from SR-BI by having a different cytoplasmic C-terminus, specifically the terminal 42 amino acids. ${ }^{21}$ SR-BI.2 mRNA levels are comparable with SR-BI in all tissues examined, although protein levels are lower. In liver, SR-BI.2 accounts for only 10\%-15\% of the SR-BI/SR-BI.2 total protein. ${ }^{22}$ Experiments in Chinese hamster ovary ( $\mathrm{CHO}$ ) cells indicate that SR-BI.2 is mostly intracellular rather than membrane bound and may be involved in within-cell cholesterol trafficking and HDL endocytosis. ${ }^{23,24}$ However, liver-specific effects and the in vivo relevance of SR-BI.2 have not been fully elucidated.

\section{Tissue expression and cellular location of SR-BI}

SR-BI is expressed in multiple tissues, including the adrenals, gonads, macrophages, endothelial cells, and liver. ${ }^{2,18,25}$ The liver, by total mass, is the primary location of SR-BI protein, and given our knowledge of HDL-CE selective uptake in the liver, determining the hepatic-specific in vivo function of SR-BI is a critical goal. Early immunohistochemical analysis of hepatocytes indicated that SR-BI is localized to the surface of hepatocytes, both at the sinusoidal and bile canalicular domains. ${ }^{26}$ This has been confirmed by others using immunohistochemistry and Western blot-based studies. ${ }^{27-29}$ In addition, it has been shown in purified membrane fractions that SR-BI is present in both canalicular membranes and basolateral membranes, ${ }^{30}$ and, when stimulated by cholesterol, SR-BI undergoes transcytosis to the bile canaliculus. ${ }^{31}$

In $\mathrm{CHO}$ cells, SR-BI colocalizes with caveolae ${ }^{12,32}$ and preferentially, but not exclusively, colocalizes and copurifies with the major caveolae protein component caveolin-1 (CAV-1). ${ }^{12}$ Caveolae are low-density, 50-100 nm invaginated plasma membrane microdomains enriched in cholesterol as well as glycolipids relative to the remainder of the plasma membrane in general. ${ }^{33}$ As these membrane microdomains have been shown to be important in mediating many transport and signaling events, including the subcellular transport of cholesterol and cholesterol efflux from cells, the colocalization of SR-BI with membrane caveolae may substantially modulate its selective lipid uptake activity in various tissues and cell types. ${ }^{12,34}$

However, later studies examining rat adrenal ${ }^{35}$ and ovary tissue $^{36}$ in vivo showed that caveolae are less significant 
for the localization of SR-BI and that SR-BI is localized to plasma membrane microvillar channel-like structures. Indeed, in adrenocortical cells, it appears that SR-BI is a prerequisite for the formation of these structures. ${ }^{37}$ It was also demonstrated in vitro using adrenocortical cells that SR-BI does not colocalize with caveolae but rather it nonuniformly clusters on microvillar extensions that lack CAV-1 expression. ${ }^{38}$ Furthermore, in kidney and thyroid cell lines, CAV-1 expression does not affect SR-BI-mediated selective uptake of $\mathrm{CE} .{ }^{39}$ It is noteworthy that there is comparatively very little CAV-1 in mouse liver, and the homologs CAV-2 and CAV-3 are completely absent. ${ }^{40,41}$ There have been very few studies examining the relationship of SR-BI and caveolae in the liver.

In humans, immunohistochemisty of samples from autopsied cadavers has revealed that human SR-BI is present in both hepatocytes and Kupffer cells, which are liver-specific macrophages. In addition, SR-BI is present in human atherosclerotic aortas and coronary arteries, which are essentially all the key tissues for reverse cholesterol transport (RCT). ${ }^{25}$ Despite this basic characterization of human SR-BI in vitro, almost all of our functional in vivo knowledge of SR-BI is derived from animal models.

\section{In vivo SR-BI characterization}

Functional in vivo characterization of SR-BI, and hepatic SR-BI function in particular, has been elucidated using animal models, including rats, ${ }^{18}$ rabbits, ${ }^{42}$ and hamsters, ${ }^{43}$ but particularly mice. The primary mouse model is the wholebody $S r-b I^{-1-} \cdot{ }^{44}$ However, there are additional mouse models with reduced as well as increased $S r-b I$ expression that have proven useful in characterizing SR-BI.

\section{Liver-specific overexpression of SR-BI}

Isolating the hepatic-specific effects of SR-BI versus the extrahepatic specific effects of SR-BI has not been a trivial endeavor, and indeed some of the earlier studies to examine liver-specific SR-BI function utilized overexpression of SR-BI (Table 1). ${ }^{26,45-48}$ Overexpression of SR-BI by adenovirus in mouse liver results in decreased plasma HDL and APOAI levels, increased hepatic uptake of DiI-label from HDL, and increased biliary cholesterol. ${ }^{26}$ Stable transgenic mice with hepatic SR-BI overexpression (Sr-bI.Tg) show similar results along with decreased APOAII, increased CE-selective uptake in liver, increased uptake of HDL protein in both liver and kidney, and decreased VLDL and LDL-CE and APOB levels by up to $97 \%$. These results demonstrate that the effects on APOB levels are not trivial and could influence the outcome of atherosclerosis beyond the effects of HDL. ${ }^{46}$ Additional studies in various overexpression models also show the non-HDL cholesterol decrease presented as decreased APOB, LDL, and VLDL. ${ }^{45,47,48}$ A study examining SR-BI overexpression in the background of human APOB transgenic mice revealed some complex diet-dependent responses and showed that with two-fold SR-BI overexpression, mice have reduced atherosclerosis, but with higher levels of SR-BI protein expression (10-fold), there was no decrease in lesion size compared with controls (Table 1). ${ }^{49}$

\section{Whole-body $\mathrm{Sr}-\mathrm{bl}^{-1-}$ mice}

The whole-body KO displays increased total plasma cholesterol, and on a standard chow diet, that increased cholesterol is distributed wholly in the HDL fractions. ${ }^{44}$ Other lipid changes that are common in the $S r-b I^{-/-}$mice include increased plasma-free cholesterol, HDL-CE, and a decrease in biliary cholesterol. Interestingly, there are no changes in hepatic lipids, triglycerides, free cholesterol, and CE, or in plasma triglycerides. ${ }^{44,50}$ Mice placed on a high-fat Western diet for 20 weeks show a significant increase in aortic lesions, proving that SR-BI deficiency in mice is proatherogenic. ${ }^{50}$ In the absence of APOE $\left(S r-b I^{-/} A p o e^{-/-}\right.$double knockout [dKO] mice), lesion size and plasma cholesterol are raised even higher than in either single KO strains. ${ }^{51}$ The dKO mice suffer severe cardiac dysfunction, resulting in premature death. ${ }^{52}$ However, HDL and HDL cholesterol in the dKO mice is significantly reduced, with almost no normal-sized HDL particles. Total APOAI levels are reduced only slightly in the $\mathrm{dKO}$ mice; however, the distribution of APOAI is more in the intermediate-density lipoprotein/LDL and VLDL fractions (Table 2).

\section{Liver-specific knockdown of SR-BI}

Knockdown mouse models beyond the whole-body $S r-b I^{-1-}$ have also been developed to study SR-BI function. A knockdown model targeting the promoter region (Sr-bI.att) was generated, resulting in approximately $50 \%$ reduction of SR-BI protein levels in all tissues examined, including liver, adrenals, and testis. These mice show increased HDL and total cholesterol with decreased HDL-CE selective uptake, as expected. However, in contrast to the overexpression models, there are no changes in VLDL, LDL, and APOB. ${ }^{53}$ This strain was examined for atherosclerosis susceptibility by crossing it on to the $L_{d l r^{-/}}$background. ${ }^{54}$ The authors observed a 50\%-70\% increase in plasma cholesterol that was attributed mostly 
Table I Hepatic overexpression of SR-BI in mice

\begin{tabular}{|c|c|c|c|c|}
\hline Strain (background) & Diet & Phenotype & Direction & Ref \\
\hline \multirow[t]{2}{*}{ Ad.mSr-bl (C57BL/6]) } & Chow & HDL-C & $\downarrow$ & 26 \\
\hline & & Biliary cholesterol & $\uparrow$ & \\
\hline \multirow[t]{4}{*}{ Sr-bl.Tg (C57BL/6]) } & Chow & HDL-C & $\downarrow$ & 46 \\
\hline & & APOAI, APOAII & $\downarrow$ & \\
\hline & & VLDL, LDL, APOB & $\downarrow$ & \\
\hline & $\mathrm{HF} \mathrm{HC}$ & APOB & $\leftrightarrow$ & \\
\hline \multirow[t]{3}{*}{ Sr-bl.Tg Ldlr-l- (C57BL/6]) } & $\mathrm{HF} \mathrm{HC}$ & HDL-C, LDL & $\downarrow$ & 48 \\
\hline & & VLDL & $\uparrow$ & \\
\hline & & Lesion size & $\leftrightarrow$ & \\
\hline \multirow[t]{3}{*}{ Sr-bl.Tg Ldlr-I+ (C57BL/6]) } & $\mathrm{HF} \mathrm{HC}+\mathrm{CA}$ & HDL-C & $\downarrow$ & \\
\hline & & VLDL, LDL & $\downarrow$ & \\
\hline & & Lesion size & $\downarrow$ & \\
\hline \multicolumn{5}{|l|}{ Combined analysis } \\
\hline \multirow[t]{6}{*}{ Sr-bl (FVB Bac transgenics) } & Chow (6 weeks of age) & HDL-C & $\downarrow$ & 47 \\
\hline & & HDL, LDL, VLDL particle size & $\downarrow$ & \\
\hline & & APOB, non-HDL-C & $\downarrow$ & \\
\hline & & Increased LDL clearance & $\uparrow$ & \\
\hline & $\mathrm{HF} \mathrm{HC}+\mathrm{CA}$ (+4 weeks) & HDL-C & $\downarrow$ & \\
\hline & & APOB & $\downarrow$ & \\
\hline Sr-bl (FVB Bac transgenics with & Chow (6 weeks of age) & HDL, TC, non-HDL & $\downarrow$ & 49 \\
\hline \multirow[t]{6}{*}{ hAPOB.Tg) } & & mAPOB & $\leftrightarrow$ & \\
\hline & & hAPOB & $\downarrow$ & \\
\hline & $\mathrm{HF} \mathrm{HC}+\mathrm{CA}(+18$ weeks $)$ & $\mathrm{HDL}$ & $\downarrow$ & \\
\hline & & Lesion size (low SR-BI exp) & $\downarrow$ & \\
\hline & & TC, non-HDL m/hAPOB & $\leftrightarrow$ & \\
\hline & & Lesion size (high SR-BI exp) & $\leftrightarrow$ & \\
\hline \multirow[t]{3}{*}{ Ad.mSr-bl Ldlr-I- (C57BL/6]) } & HF HC (no CA) & HDL-C, APOAI & $\downarrow$ & 45 \\
\hline & & LDL-C (FPLC) & $\downarrow$ & \\
\hline & & Lesion size & $\downarrow$ & \\
\hline \multirow[t]{4}{*}{ Ad.mSr-bl hAPOB.Tg } & Chow & HDL-C (24-72 h) & $\downarrow$ & 137 \\
\hline & & TC (72 hours) & $\downarrow$ & \\
\hline & & HDL-C (FPLC at 72 hours) & $\downarrow$ & \\
\hline & & $\mathrm{APOB}$ & $\leftrightarrow$ & \\
\hline \multirow[t]{4}{*}{ Ad.mSr-bl (C57BL/6]) } & Chow & $\mathrm{HDL}$ & $\downarrow$ & 58 \\
\hline & & $\mathrm{TC}, \mathrm{FC}$ & $\downarrow$ & \\
\hline & & TG, phospholipids & $\downarrow$ & \\
\hline & & APOB, VLDL & $\downarrow$ & \\
\hline Ad.hSR-BI & Chow & RCT to liver and feces & $\uparrow$ & 79 \\
\hline \multicolumn{5}{|l|}{ hAPOAI.Tg (C57BL/6]) } \\
\hline \multirow[t]{9}{*}{ Ad.mSr-bl (C57BL/6]) } & Chow & $\mathrm{TC}$, day 3,7 , and $\mathrm{I} 4$ & $\downarrow$ & 65 \\
\hline & & TG day 3 & $\downarrow$ & \\
\hline & & TG day 7,14 & $\uparrow$ & \\
\hline & & VLDL-C (FPLC) day 7 and 14 & $\uparrow$ & \\
\hline & & LDL-C (FPLC) day 3,7 , and I4 & $\uparrow$ & \\
\hline & & Hepatic VLDL-TG production & $\uparrow$ & \\
\hline & & Hepatic VLDL-APOB production & $\uparrow$ & \\
\hline & & Liver weight as \% bodyweight & $\uparrow$ & \\
\hline & & HDL-C resecreted by liver in VLDL & $\uparrow$ & \\
\hline
\end{tabular}

Abbreviations: APO, apolipoprotein; CA, cholic acid; FPLC, fast protein liquid chromatography; HC, high cholesterol; HDL-C, high-density lipoprotein cholesterol; HF, high fat; LDL, low-density lipoprotein; RCT, reverse cholesterol transport; SR-BI, scavenger receptor class B member I; TG, triglycerides; TC, total cholesterol; VLDL, very low-density lipoprotein.

to non-HDL cholesterol, accompanied by significantly elevated atherosclerosis, with only a slight but significant increase in HDL. The authors also showed that SR-BI in vivo did not mediate selective uptake of CE from LDL, nor did it affect LDL catabolism or plasma LDL clearance.
The authors point toward the increased LDL production as the cause of the observed atherosclerosis, probably arising from increased conversion of VLDL-CE to LDL-CE, which, in turn, may be caused by the "backup function" of SR-BI to take up VLDL remnants. ${ }^{54}$ 
Table 2 Key Sr-bl'- mouse models and studies

\begin{tabular}{|c|c|c|c|c|c|}
\hline Strain & Control strain & Diet & Phenotype & Direction & Ref \\
\hline \multirow[t]{3}{*}{$\overline{S r-b l-I-}$} & Sr-bl+l+ & Chow & TC, HDL & $\uparrow$ & 44 \\
\hline & & & Total APOAI & $\leftrightarrow$ & \\
\hline & & & Adrenal cholesterol & $\downarrow$ & \\
\hline Sr-bl-I- & $S r-b l+1+$ & Chow & $\mathrm{TC}$ & $\uparrow$ & 51 \\
\hline \multirow{4}{*}{ Apoe-I- } & Apoe-1- & & VLDL cholesterol (FPLC) & $\uparrow$ & \\
\hline & & & Lesion size & $\uparrow$ & \\
\hline & & & HDL, APOAI & $\downarrow$ & \\
\hline & & & Biliary cholesterol & $\downarrow$ & \\
\hline Sr-bl-I- & $S r-b l+1+$ & Chow & Increased premature death & $\uparrow$ & 52 \\
\hline \multirow[t]{2}{*}{ Apoe-1- } & Apoe-1- & & Occlusive athero CAD & $\uparrow$ & \\
\hline & & & Body size & $\downarrow$ & \\
\hline \multirow[t]{6}{*}{ Sr-bl-I- } & $S r-b l+l+$ & Chow followed by WTD ( 20 weeks) & $\mathrm{TC}, \mathrm{FC}$ & $\uparrow$ & 50 \\
\hline & & & HDL-CE & $\uparrow$ & \\
\hline & & & TG & $\leftrightarrow$ & \\
\hline & & & Lesion size & $\uparrow$ & \\
\hline & & & Hepatic TG, FC, CE & $\leftrightarrow$ & \\
\hline & & & Biliary cholesterol & $\downarrow$ & \\
\hline$S r-b l-1-$ & Ldlr-I- & High-fat diet ( 12 weeks) & $\mathrm{TC}$ & $\uparrow$ & 74 \\
\hline \multirow[t]{3}{*}{ Ldlr-I- } & & & $\mathrm{HDL}$ & $\uparrow$ & \\
\hline & & & Lesion size & $\uparrow$ & \\
\hline & & & VLDL cholesterol & $\leftrightarrow$ & \\
\hline Sr-bl-l- & $S r-b l+1+$ & Chow & RCT to liver and feces & $\uparrow$ & 79 \\
\hline \multirow[t]{4}{*}{ Sr-bl-I- } & Sr-bl+l+ & Chow & Hepatic VLDL-TG production & $\downarrow$ & 65 \\
\hline & & & Hepatic VLDL-APOB production & $\downarrow$ & \\
\hline & & & $\mathrm{TC}$ and $\mathrm{FC}$ & $\uparrow$ & \\
\hline & & & HDL-C resecreted by liver in VLDL & $\downarrow$ & \\
\hline
\end{tabular}

Abbreviations: APO, apolipoprotein; CAD, coronary artery disease; CE, cholesteryl ester; FC, free cholesterol; FPLC, fast protein liquid chromatography; HDL, high-density lipoprotein; LDL, low-density lipoprotein; RCT, reverse cholesterol transport; TC, total cholesterol; TG, triglycerides; VLDL, very low-density lipoprotein; WTD, Western type diet.

A second knockdown model was developed as a liver-specific SR-BI KO (hypomSr-bI $I^{\text {liver }}$ ). However, unexpectedly, SR-BI protein levels were reduced in all the tissues that were examined, not just in the liver. Phenotypically, as with the $S r$-bI.att mice, the hypomSr-bI $I^{\text {liver }}$ mice showed increased HDL and total cholesterol with decreased HDL-CE uptake and there were no changes in VLDL, LDL, and APOB levels. The hypom $S r-b I^{\text {liver }}$ mice showed increased atherosclerosis, although this was decreased compared with $\mathrm{Sr}-\mathrm{b} \mathrm{I}^{--}$(whole-body KO) mice. The authors hypothesized that this could be due to residual extrahepatic SR-BI providing atheroprotection in addition to the known liver lipoprotein function. ${ }^{55}$ If this is true, the protection is unlikely to be from macrophage SR-BI function. ${ }^{56}$ Although not explored by the authors, the observed differences in atherosclerosis of the hypom $S r$ - $b I^{\text {liver }}$ mice compared with $S r-b I^{-/-}$mice could also be due to the significantly different genetic backgrounds of the two strains.

More recently, a third model for SR-BI knockdown was reported, having been identified through a mutagenesis screen: the $S r-b I^{1179 \mathrm{~N}}$ mutant mice. This strain has $90 \%$ knockdown of SR-BI protein in the liver with no knockdown in adrenals or ovaries caused by a single nucleotide mutation in the 179th amino acid. ${ }^{57}$ This strain differs from the other two knockdown strains, as well as the $S r-b I^{--}$strain, by being in a pure C57BL/6 background, allowing for a more direct comparison with the transgenic overexpression models $\mathrm{Sr}$ bI.Tg, ${ }^{46,48}$ as well as the somatic adenovirus liver transgenic studies ${ }^{26,45,58} \mathrm{HDL}$, total cholesterol, and free cholesterol in $S r-b I^{1179 \mathrm{~N}}$ mice are significantly increased with an accompanying decrease in selective uptake, as expected, compared with wildtype controls. In addition, an increase in phospholipids is observed (also indicated in the Sr-bI.att mice), as well as, for the first time, a significant increase in triglycerides, noting that somatic liver adenovirus overexpression of SR-BI (Ad.mSr-bI) leads to decreased phospholipids and triglycerides (Table 1). ${ }^{58}$ The effects on atherosclerosis and APOB lipoproteins have not yet been reported for this strain (Table 3).

\section{"Humanizing" SR-BI mouse models by introducing CETP}

The mouse is not a perfect model for human lipid and atherosclerosis studies. A key missing component in mice is the 
Table 3 Knockdown of SR-BI in mice

\begin{tabular}{|c|c|c|c|c|c|}
\hline Strain (background) & Diet & Tissue specificity & Phenotype & Direction & Ref \\
\hline $\begin{array}{l}\text { Sr-blatt } \\
\text { (BALB/cByJ) } \\
\text { promoter mutation }\end{array}$ & Chow & Liver, adrenal, testis & $\begin{array}{l}\text { HDL,TC } \\
\text { HDL particle size } \\
\text { Phospholipids } \\
\text { APOAl } \\
\text { 3H CE clearance } \\
\text { Selective uptake } \\
\text { TG } \\
\text { VLDL, APOB, APOE }\end{array}$ & $\begin{array}{l}\uparrow \\
\uparrow \\
\uparrow \\
\uparrow \\
\downarrow \\
\downarrow \\
\leftrightarrow \\
\leftrightarrow\end{array}$ & 53 \\
\hline $\begin{array}{l}\text { Sr-blatt Ldlr-I- } \\
\text { (BALB, C57BL6 mix) }\end{array}$ & Chow or HF $+\mathrm{HC}$ & Liver, adrenal, testis & $\begin{array}{l}\text { HDL, TC } \\
\text { LDL, APOB } \\
\text { Lesion size } \\
\text { Clearance: APOB, APOE } \\
\text { TG }\end{array}$ & $\begin{array}{l}\uparrow \\
\uparrow \\
\uparrow \\
\leftrightarrow \\
\leftrightarrow\end{array}$ & 54 \\
\hline $\begin{array}{l}\text { hypomSr-bl-KOliver } \\
\text { flox/cre }\end{array}$ & Chow & $\begin{array}{l}\text { Liver, kidney, adrenal, testis, } \\
\text { ovary, aorta, BMM }\end{array}$ & $\begin{array}{l}\text { HDL, TC, } \\
\text { FC }\end{array}$ & $\uparrow$ & 55 \\
\hline $\begin{array}{l}\text { liver conditional } \\
\text { knockout }(129, \text { C57BL/6 mix })\end{array}$ & & & $\begin{array}{l}\mathrm{FC} / \mathrm{TC} \\
\mathrm{TG}\end{array}$ & $\begin{array}{l}\uparrow \\
\leftrightarrow\end{array}$ & \\
\hline & $\mathrm{HF} \mathrm{HC}+\mathrm{CA}$ & & $\begin{array}{l}\text { TC } \\
\text { FC } \\
\text { FC/TC\% } \\
\text { TG } \\
\text { Lesion size }\end{array}$ & $\begin{array}{l}\uparrow \\
\uparrow \\
\uparrow \\
\uparrow\end{array}$ & \\
\hline $\begin{array}{l}\text { Sr-bl'179N } \\
(C 57 B L / 6 J)\end{array}$ & Chow & Liver & $\begin{array}{l}\text { HDL, APOAI } \\
\text { TC FC, FC/TC } \\
\text { TG phospholipids } \\
\text { 3H CE clearance } \\
\text { Selective uptake }\end{array}$ & $\begin{array}{l}\uparrow \\
\uparrow \\
\uparrow \\
\uparrow \\
\downarrow \\
\downarrow\end{array}$ & 57 \\
\hline
\end{tabular}

Abbreviations: APO, apolipoprotein; BMM, bone marrow derived macrophages; CAD, coronary artery disease; CE, cholesteryl ester; FC, free cholesterol; HC, high cholesterol; HDL, high-density lipoprotein; HF, high fat; LDL, low-density lipoprotein; SR-BI, scavenger receptor class B member I; TC, total cholesterol; TG, triglycerides; VLDL, very low-density lipoprotein.

absence of cholesteryl ester transfer protein (CETP), which accounts for the vast majority of human plasma HDL cholesterol heritability. ${ }^{59}$ Consequently, an increasing component of determining the comparable human function of lipid genes is the use of more humanized mouse models. Several studies have examined the absence of SR-BI in the presence of CETP using CETP transgenic mouse models (CETP.Tg). One study that introduced CETP.Tg with a liver-specific hAPOA1-promoter into the $S r-b I^{-/-}$genetic background fed the mice a cholate-free atherogenic diet and showed that the CETP expression reduced atherosclerosis. This is likely due to the movement of cholesterol away from the enlarged dysfunctional HDL in $S r-b I^{-1-}$ to APOB-containing lipoproteins, clearing the cholesterol via alternative reverse cholesterol pathways such as the LDL receptor ${ }^{60}$ and other LDL-independent pathways. ${ }^{61}$ Controversially, a more recent study using a similar approach but using CETP.Tg mice with the human endogenous CETP promoter (endoCETP.Tg), rather than a liver-specific promoter, ${ }^{62}$ showed no reduction in atherosclerosis despite an increase in HDL-CE transfer to the liver. ${ }^{63}$ In both of these studies of $\mathrm{Sr}-b \mathrm{I}^{-/} \mathrm{CETP}$.Tg and $S r-b I^{-1-}$ endoCETP.Tg, the mice involved have wildtype LDL receptor and APOE, which means they are not particularly prone to atherosclerosis. Further studies are required to delineate whether or not CETP is antiatherogenic in the absence of SR-BI (Table 4).

\section{In vivo hepatic SR-BI: effects on APOB- containing lipoproteins and bidirectional flux of free cholesterol}

Clearly, a major function of SR-BI is the selective uptake of HDL-CE; however, as discussed previously for the overexpression studies, SR-BI has a distinct role in APOBcontaining lipoprotein metabolism, especially with regard to VLDL and chylomicrons. ${ }^{46,47,49,58,64-67}$ In almost all mouse liver overexpression studies (Table 2), combinations of VLDL, APOB, total cholesterol, and triglycerides were all affected. The resulting changes in atherosclerosis susceptibility could therefore be due to changes in atherogenic APOB lipoproteins. Studies using radiolabeled VLDL have shown that SR-BI has a major role in VLDL remnant uptake in vivo (as well as in vitro) that does not involve selective 
Table 4 "Humanized" SR-BI mouse models

\begin{tabular}{|c|c|c|c|c|c|}
\hline Strain & Diet & Control & Phenotype & Direction & Ref \\
\hline Sr-bl-I- & Chow (6-8 weeks) followed & Sr-bl-l- & Lesion size & $\downarrow$ & 60 \\
\hline \multirow[t]{3}{*}{ CETP.Tg } & by Western diet for 22 weeks & & $\mathrm{TC}$ & $\downarrow$ & \\
\hline & & & Hepatic CE & $\downarrow$ & \\
\hline & & & Hepatic FC, esterified cholesterol & $\leftrightarrow$ & \\
\hline Sr-bl-I- endo & Chow & WT mice and Sr-bl-I- & HDL, TC, FC & $\downarrow$ & 63 \\
\hline \multirow[t]{9}{*}{ CETP.Tg } & & & $\mathrm{FC} / \mathrm{TC} \%$ & $\downarrow$ & \\
\hline & & & VLDL & $\downarrow$ & \\
\hline & & & LDL & $\leftrightarrow$ & \\
\hline & & WT mice only & LDL & $\downarrow$ & \\
\hline & Western diet & WT mice and Sr-bl-I- & HDL, TC, FC & $\downarrow$ & \\
\hline & & & $\mathrm{FC} / \mathrm{TC} \%$ & $\downarrow$ & \\
\hline & & & VLDL, LDL & $\leftrightarrow$ & \\
\hline & & WT mice only & VLDL, LDL & $\downarrow$ & \\
\hline & & Sr-bl-l- & Lesion size & $\leftrightarrow$ & \\
\hline
\end{tabular}

Abbreviations: CE, cholesteryl ester; CETP, cholesteryl ester transfer protein; FC, free cholesterol; HDL, high-density lipoprotein; LDL, low-density lipoprotein; SR-BI, scavenger receptor class B member I; TC, total cholesterol; Tg, transgenic; VLDL, very low-density lipoprotein.

uptake. ${ }^{65,67}$ It is also believed that reduced hepatic SR-BI leads to reduced VLDL-triglyceride and VLDL-APOB in vivo production, indicating that hepatic SR-BI HDL-derived cholesterol is affected by SR-BI in hepatocytes in the form of VLDL particles (Figure 2, red arrows). ${ }^{65}$

\section{Reverse cholesterol transport}

The complete RCT pathway ${ }^{68}$ involves many proteins, including enzymes, apolipoproteins, receptors, and transporters. These function to return cholesterol from lipid-laden macrophages and peripheral tissues to the liver for secretion via the bile and feces. However, the individual steps of the RCT pathway can be assessed separately to determine the effects due to individual proteins. These include the removal of cholesterol from macrophages to lipoproteins, considered the governing and first step of RCT; the removal of HDL-CE from lipoproteins to the liver, governed in large part by SR$\mathrm{BI} ;{ }^{69}$ and the removal of cholesterol from bile to the feces. ${ }^{70}$ The purpose of examining individual aspects of the RCT pathway allows the assessment of individual, specific proteins

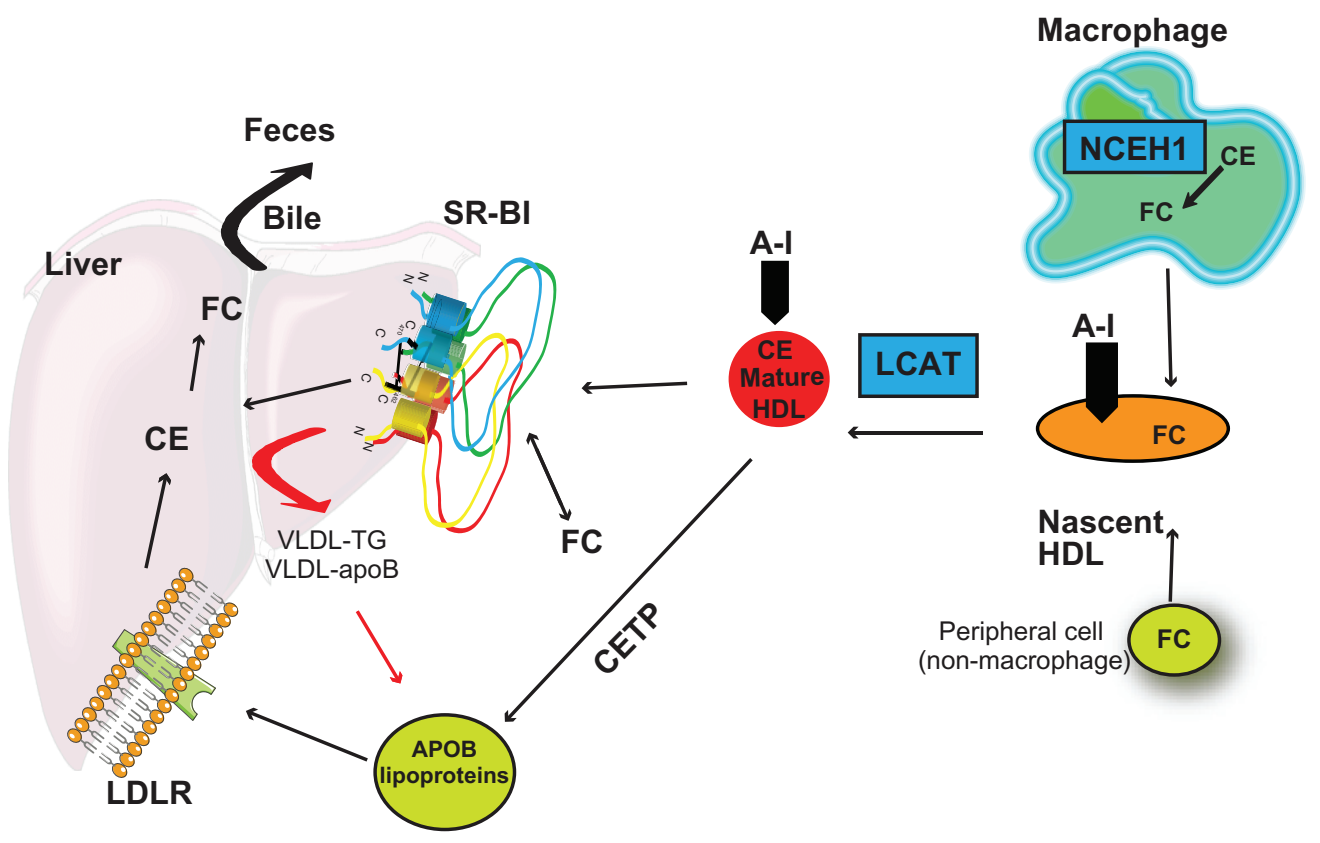

Figure 2 Reverse cholesterol transport. SR-BI selective HDL-CE uptake is crucial in the clearance of cholesterol from macrophages and peripheral tissue, reducing the incidence of atherosclerosis.

Abbreviations: CE, cholesteryl ester; CEH, cholesteryl ester hydrolase; CETP, cholesteryl ester transfer protein; FC, free cholesterol; HDL, high-density lipoprotein; LCAT, lecithin cholesterol acyltransferase; LDL, low-density lipoprotein; LDLR, low-density lipoprotein receptor; NCEH, neutral cholesteryl ester hydrolase; SR-BI, scavenger receptor class B member I; VLDL, very low-density lipoprotein. 
to be characterized without necessarily following the cholesterol all the way to the feces, where it is difficult and tedious to measure. Figure 2 provides an overview of RCT.

\section{RCT:SR-BI in macrophages}

SR-BI is critical for the uptake of CE to the liver; however, SR-BI is also present in the macrophages, ${ }^{1}$ and the removal of cholesterol from macrophages is a critical component of reducing atherosclerosis. RCT can be examined in vivo by using macrophage foam cells that are loaded with radiolabeled cholesterol. ${ }^{71}$ The cells are injected intraperitoneally, and the cholesterol is effluxed by lipoproteins to different tissues. Interestingly, murine macrophages also seem to exhibit HDL-CE selective uptake that is independent of SR-BI. ${ }^{72}$ In vivo studies have examined the potential of macrophage SR-BI to promote RCT. ${ }^{56}$ However, primary bone marrowderived macrophages (BMMs), as well as mouse peritoneal macrophages (MPMs) from $S r-b I^{-/-}$mice, showed no net effect on RCT compared with wildtype mice. Furthermore, MPMs show very little SR-BI-dependent efflux capacity. ${ }^{73}$ This indicates that the impact on atherosclerosis attributable to SR-BI is primarily due to its liver function, rather than to function in the macrophages. However, studies using BMM transplants have shown that macrophage SR-BI may yet play a role in atherosclerosis development (Table 5). When BMMs derived from $\mathrm{Sr}-b \mathrm{I}^{-/-}$mice are transplanted into $\mathrm{Ldlr}^{-/-}$or Apoe $^{-/-}$mice, atherosclerosis increases. ${ }^{74-76}$ This may be due to changes in cholesterol efflux capacity and/or inflammation. Interestingly, VLDL and LDL cholesterol strangely increases in mice transplanted with BMMs derived from $\mathrm{Sr}_{-} b I^{-/-}$mice, whereas HDL cholesterol is unchanged when compared with $L d l r^{-/-}$mice transplanted with wildtype BMMs.

\section{RCT: SR-BI in hepatocytes}

Although SR-BI in liver acts as an acceptor for HDL-CE, it has also been shown in vitro to efflux cholesterol, ie, to move cholesterol out of cells on to HDL. This cholesterol efflux function of SR-BI has been observed only in nonmacrophage cell lines. ${ }^{2,77,78}$ Studies performed to specifically observe the same function in macrophages have shown that SR-BI is not involved in cholesterol efflux ${ }^{72}$ or that efflux is minimal, with bidirectional flux favoring influx. ${ }^{73}$ In vivo overexpression of SR-BI in mouse hepatocytes results in increased RCT from radiolabeled cholesterol-loaded macrophages, leading

Table 5 Bone marrow transplant studies examining SR-BI

\begin{tabular}{|c|c|c|c|c|c|c|}
\hline \multicolumn{3}{|l|}{ Strain } & \multirow[t]{2}{*}{ Diet } & \multirow[t]{2}{*}{ Phenotype } & \multirow[t]{2}{*}{ Direction } & \multirow[t]{2}{*}{ Ref } \\
\hline BMM donor & Control & BMM recipient & & & & \\
\hline \multirow[t]{3}{*}{ Sr-bl-I- } & Sr-bl+/+ & Ldlr-I- & $\begin{array}{l}\text { Western diet } 4 \text { weeks after } \\
\text { transplant for } 16 \text { weeks }\end{array}$ & $\begin{array}{l}\text { VLDL and IDL/LDL } \\
\text { Cholesterol (FPLC) }\end{array}$ & $\uparrow$ & 74 \\
\hline & & & & Lesion size & $\uparrow$ & \\
\hline & & & & HDL cholesterol (FPLC) & $\leftrightarrow$ & \\
\hline Sr-bl-I- & Sr-bl+l+ & Apoe-1- & Baseline, 4,8 , and 12 weeks & Lesion size & $\uparrow$ & 138 \\
\hline \multirow[t]{3}{*}{ Apoe-I- } & Apoe-I- & & post-transplant & $\mathrm{TC}, \mathrm{TG}$ & $\leftrightarrow$ & \\
\hline & & & & VLDL and IDL/LDL & & \\
\hline & & & & Cholesterol (FPLC) & $\leftrightarrow$ & \\
\hline \multirow[t]{4}{*}{ Sr-bl-I- } & Sr-bl+/+ & Ldlr-/- & Chow, Western diet & Lesion size & $\uparrow$ & 75 \\
\hline & & & Western diet 9-12 wks & HDL, FC, CE & $\leftrightarrow$ & \\
\hline & & C57BL/6] & Chow & HDL, FC, CE & $\leftrightarrow$ & \\
\hline & & & Paigen diet & Lesion size & $\uparrow$ & \\
\hline \multirow[t]{2}{*}{ Sr-bl-I- } & Sr-bl+/+ & C57BL/6] & Chow & Reverse cholesterol & $\leftrightarrow$ & 56 \\
\hline & & & & Transport & & \\
\hline Sr-bl-I- and Sr-bl-I- & $S r-b l+/+$ & Ldlr-/- & Chow, 8 weeks & $\mathrm{TC}$ & $\leftrightarrow$ & 76 \\
\hline \multirow[t]{7}{*}{ Abcal-I- } & & & post transplant & $\begin{array}{l}\text { VLDL, LDL, HDL } \\
\text { cholesterol (FPLC) }\end{array}$ & $\leftrightarrow$ & \\
\hline & & & Western diet for 10 weeks, & Lesions in aortic root & $\uparrow$ & \\
\hline & & & 18 weeks post-transplant & Lesions in aortic arch, & $\leftrightarrow$ & \\
\hline & & & & HDL cholesterol (FPLC) & $\leftrightarrow$ & \\
\hline & & & & Lesions in thoracic root & $\downarrow$ & \\
\hline & & & & $\mathrm{TC}$ & $\downarrow$ & \\
\hline & & & & $\begin{array}{l}\text { VLDL, LDL cholesterol } \\
\text { (FPLC) }\end{array}$ & $\downarrow$ & \\
\hline
\end{tabular}

Abbreviations: BMM, bone marrow-derived macrophage; CE, cholesteryl ester; FC, free cholesterol; FPLC, fast protein liquid chromatography; HDL, high-density lipoprotein; IDL, intermediate-density lipoprotein; LDL, low-density lipoprotein; SR-BI, scavenger receptor class B member I; TC, total cholesterol; TG, triglycerides; VLDL, very low-density lipoprotein. 
to increased clearance to the liver and ultimately the feces. This has been observed in wildtype C57BL/6J mice as well as in hAPOAI.Tg mice. Conversely, in $\mathrm{Sr}^{-} \mathrm{bI^{-/- }}$ mice, RCT is reduced, resulting in decreased clearance from macrophages to the liver and feces. ${ }^{79}$ Although the exact mechanism as to how hepatic SR-BI affects RCT from macrophages is not clear, the authors suggest that SR-BI may act on HDL to generate remnant HDL particles or lipid-poor APOAI, which may be better acceptors of cholesterol efflux from macrophages. ${ }^{79}$

\section{Hepatic regulation of SR-BI}

Given our knowledge of how hepatic SR-BI can influence RCT through HDL-CE selective uptake (and possibly through proatherogenic APOB-containing lipoproteins), it is important that we understand how hepatic SR-BI protein levels are regulated. Indeed, multiple regulatory pathways have been identified to act at the protein level, as well as through multiple independent transcriptional pathways (Figure 3).

\section{Protein regulation through PDZKI}

A significant mechanism by which hepatic SR-BI protein levels are regulated is by the adaptor protein PDZ domain containing 1 (PDZK1, also known as C-terminal linking and modulating protein [CLAMP]). PDZK1 was the only protein identified to interact with SR-BI in a yeast two-hybrid screen. ${ }^{27}$ Several studies have shown that the first of the four PDZ domains in PDZK1 (N-terminal) is critical for its binding to SR-BI and possibly promotes SR-BI translocation to the sinusoid. ${ }^{27}$ The binding occurs at SR-BI's C-terminus, with the terminal amino acid (509) being especially critical, not only for the interaction but also for the cell surface expression of SR-BI in vivo. ${ }^{27,80}$ PDZK1 does not interact with SR-BI.2, which has an alternative C-terminus. PDZK1 itself is regulated by a small PDZK1-associated protein (SPAP, also known as DD96/MAP17). Overexpression of SPAP in mice by adenovirus leads to decreased PDZK1 and decreased SR-BI liver protein levels. ${ }^{81}$ In vitro evidence suggests that PDZK1 expression is upregulated by peroxisome proliferator-activated receptor (PPAR) $\alpha .^{82}$

Whole-body KO mice for PDZK1 (Pdzkl $\left.1^{--}\right)$have elucidated further effects and mechanisms of this interaction..$^{83}$ $P d z k 1^{-1-}$ mice have a $95 \%$ reduction of hepatic SR-BI protein levels and a $50 \%$ reduction in the proximal intestine, but in the steroidogenic tissues, adrenals, testis, and ovaries, SR-BI levels are unchanged. Due to the $95 \%$ hepatic SR-BI reduction, many of the resulting lipid phenotypes are unsurprising, such as the increased total cholesterol and free cholesterol. Phospholipids are also significantly increased, and triglycerides are increased in females. In the absence of PDZK1 and APOE (Pdzkl $1^{-1-} \mathrm{Apoe}^{-1-} \mathrm{dKO}$ mice), aortic atherosclerotic lesions $^{84}$ and occlusive coronary artery disease (CAD) are

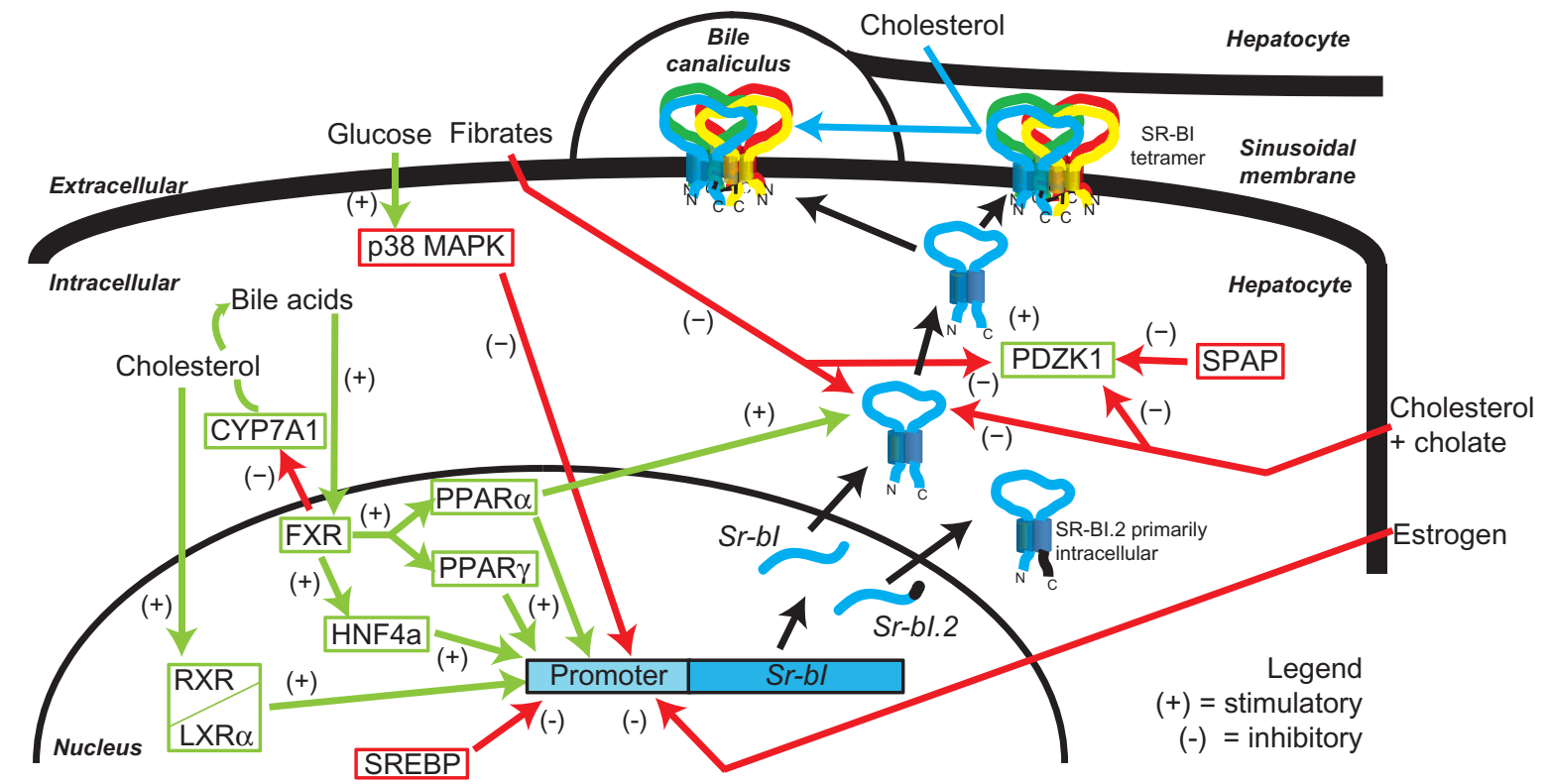

Figure 3 Mechanisms affecting SR-BI member I regulation. Green arrows and positive signs indicate that interaction increases the activity or abundance of the downstream element, and red arrows and negative signs indicate decreased function and abundance. The blue arrow indicates possible transcytosis to the bile canaliculus activated by cholesterol. Black arrows show the normal path of SR-BI to the membrane. Note that although fibrates increase PPARs, this does not translate to increased SR-BI, because the net effect is reduced hepatic SR-BI protein levels.

Abbreviations: CYP7AI, cholesterol 7-anhydroxylase; FXR, farnesoid X receptor; HNF4a, hepatic nuclear factor 4, alpha; LXR, liver X receptor; MAPK, mitogen-activated protein kinase; PPAR, proliferator-activated receptor; RXR, retinoid X receptor; SPAP, small PDZKI-associated protein; SR-BI, scavenger receptor class B member I; SREBP, sterol regulatory element binding protein. 
significantly increased. ${ }^{85}$ Interestingly, in the dKO mice maintained on a Western atherogenic diet for 5 months, hepatic SR-BI protein remained significantly down $(\sim 93 \%)$, but there was no difference in total cholesterol. In addition, fast protein liquid chromatography analysis showed that VLDL cholesterol was slightly reduced, as opposed to increased in $\mathrm{Sr}-\mathrm{bI}^{-/-} \mathrm{Apoe}^{-/-} \mathrm{dKO}$ mice, and no occlusive atherogenic CAD was observed. Many reasons could explain the lack of occlusive atherogenic CAD, including differences in the genetic backgrounds of $S r-b I^{-/} A p o e^{-/-}$vs $P d z k 1^{-/} A p o e^{--}$, the protective effects of extrahepatic SR-BI in the $P d z k 1^{-/}$mice, or even the protective effect of the residual hepatic SR-BI (7\%) in $P d z k 1^{-1-}$ mice (Table 6).

\section{Transcriptional regulation by farnesoid $X$ receptor}

The farnesoid X receptor (FXR, gene name $\mathrm{Nr} 1 \mathrm{~h} 4$ ) is a member of the nuclear receptor super-family and is highly expressed in the liver. It was shown in vitro and in vivo that FXR activation upregulates SR-BI mRNA and protein expression in cultured hepatocytes ${ }^{86}$ and that FXR-deficient mice $\left(\mathrm{Nr} 1 \mathrm{~h} 4^{-/}\right)$have significantly reduced hepatic SR-BI mRNA and protein levels. ${ }^{87}$ FXR plays an essential role in cholesterol metabolism, and genetic changes affecting FXR have proatherogenic risk. ${ }^{87} \mathrm{FXR}$ functions as a physiological sensor for bile acid (BA) and is part of a feedback loop, as it is activated by BA, which, in turn, causes the inhibition of cholesterol 7-anhydroxylase (CYP7A1), the rate-limiting enzyme in BA biosynthesis from cholesterol. ${ }^{88}$ In terms of a pathway, FXR is known to upregulate PPAR $\alpha^{89}$ and PPAR $\gamma,{ }^{90}$ which, in turn, increases SR-BI expression. ${ }^{91} \mathrm{Nr} 1 \mathrm{~h} 4^{-/-}$mice have increased plasma cholesterol, triglycerides, and CE, consistent

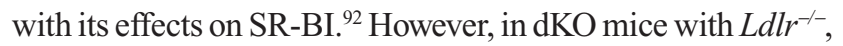

atherosclerosis was reduced in males (although not in females), even though plasma lipid levels were increased..$^{93}$ This likely reflects the complexity of the effects that FXR exerts on other lipid genes, and possibly in macrophages and atherosclerotic plaque development, beyond its direct liver effects.

\section{Transcriptional regulation by $L X R$ and $R X R$}

Additional transcriptional regulators have been identified for hepatic SR-BI. These include the liver X receptor (LXR) and retinoid $X$ receptor $(\mathrm{RXR})$, which are members of the nuclear receptor family of transcription factors and are closely related to the PPARs and FXR. ${ }^{94} \mathrm{LXR}$ has two isoforms ( $\alpha$, gene name $N r 1 h 3$; and $\beta$, gene name $N r 1 h 2$ ), and these form heterodimers with RXR to maintain tissue cholesterol homeostasis, affecting multiple lipid genes. ${ }^{95}$ It has also been shown that the LXR $\alpha /$ RXR heterodimer promotes both increased human SR-BI promoter activity and protein levels in hepatocytes as well as adipocytes in vitro and that this transcriptional activation is independent of sterol regulatory element binding protein (SREBP) transcriptional regulation. ${ }^{96}$ Elimination of both LXR $\alpha\left(N r 1 h 3^{-/}\right)$and APOE leads to increased plasma cholesterol and atherosclerosis. ${ }^{97}$ However, at least some of the effects on atherosclerosis are also due to the action of LXRs on lipid genes in macrophages. ${ }^{98}$

\section{Transcriptional regulation by SREBPs}

SREBP-1a-overexpressing transgenic (Srebpla Tg) mice have elevated hepatic cholesterol and triglyceride concentrations because SREBP-1a transcriptionally activates lipid-synthesizing genes in the liver. ${ }^{99}$ Srebp 1 a $\mathrm{Tg}$ mice have a 50\% reduction in hepatic SR-BI protein and mRNA levels compared with wildtype mice, indicating that SREBPs mediate transcriptional downregulation of SR-BI. ${ }^{100}$

Table 6 Alternative mouse models for SR-BI

\begin{tabular}{|c|c|c|c|c|c|}
\hline Strain & Control & Diet & Measure & Direction & Ref \\
\hline \multirow{4}{*}{$\begin{array}{l}\text { PdzkI-I- } \\
\text { I29/SvEv }\end{array}$} & $P d z k I+I+$ & Chow & TC, FC & $\uparrow$ & 83 \\
\hline & & & & & \\
\hline & & & Triglycerides, phospholipids & $\uparrow$ & \\
\hline & & & HDL particle size & $\uparrow$ & \\
\hline Pdzkl-I- & Pdzkl+l+ & Chow & FC, FC/TC \% & $\uparrow$ & 84,85 \\
\hline \multirow[t]{7}{*}{ Apoe-1- } & Apoe-1- & & $\mathrm{TC}$, triglycerides & $\leftrightarrow$ & \\
\hline & & & Phospholipids & $\leftrightarrow$ & \\
\hline & & Western diet (HF HC) & Lesion size & $\uparrow$ & \\
\hline & & & FC, FC/TC \% & $\uparrow$ & \\
\hline & & & Phospholipids & $\uparrow$ & \\
\hline & & & TC, triglycerides & $\leftrightarrow$ & \\
\hline & & & Occlusive athero CAD & $\leftrightarrow$ & \\
\hline
\end{tabular}

Abbreviations: CAD, coronary artery disease; FC, free cholesterol; $\mathrm{HC}$, high cholesterol; HDL, high-density lipoprotein; HF, high fat; SR-BI, scavenger receptor class B member I; TC, total cholesterol. 
Srebpla Tg mice challenged with an atherogenic diet led to hepatic SR-BI protein being completely eliminated, indicating that FXR/diet SR-BI regulation pathways and the SREBP SR-BI pathways are, to some extent, mutually exclusive.

\section{Transcriptional regulation by fibrates}

Fibrate drugs benefit cardiovascular health by lowering plasma triglycerides, normalizing LDL levels, and raising HDL levels in patients with dyslipidemias, ${ }^{101}$ as well as raising APOAI and APOAII. ${ }^{102,103}$ Fibrates induce transcriptional activation of PPARs, particularly PPARa, ${ }^{104,105}$ and many of the lipid effects of fibrates are likely due to this interaction. However, fibrates lower hepatic SR-BI protein levels, likely causing the net HDL increase. ${ }^{106,107}$ This appears to be due to SR-BI protein degradation that at least is partially dependent on PPARa and PDZK1. ${ }^{106}$ However, there is also evidence to suggest a PDZK1-independent mechanism that occurs in a postendoplasmic reticulum, postplasma membrane compartment and is independent of the proteasome, calpain protease, and lysosome. ${ }^{107}$ It has also been shown that fenofibrate is a potent inhibitor of SR-BI HDL lipid uptake but does not affect surface expression or intracellular membrane transport of SR-BI protein. ${ }^{108}$ There is little direct evidence of human hepatic SR-BI metabolism in patients taking fibrates; however, diabetic subjects taking fenofibrate have no difference in SR-BI protein levels in circulating monocytes. ${ }^{109}$ This is likely to be because SR-BI protein levels are considerably lower in circulating monocytes compared with in hepatocytes and do not reflect hepatocyte metabolism.

\section{Hyperglycemia}

Diabetes and hyperglycemia pose a significant risk to cardiovascular health. In patients with type 2 diabetes, cardiovascular disease (CVD) is the major cause of morbidity and mortality, and CVD risk is two- to four-fold increased over nondiabetic subjects. ${ }^{110,111}$ Administration of glucose to diabetic rats compared with to euglycemic control rats showed that hepatic expression of SR-BI is significantly decreased. This reduction appears to be under transcriptional control, as there is comparable knockdown of SR-BI mRNA and protein levels. In HepG2 cells, elevated glucose concentrations inhibit transcriptional activity of the human SR-BI promoter, possibly because high glucose induces the $\mathrm{p} 38$ mitogen-activated protein kinase (MAPK) signal transduction pathway. Expression of constitutively active MAPK in HepG2 cells inhibited SR-BI promoter activity in the presence or absence of glucose. Expression of a dominant-negative MAPK in HepG2 cells exposed to high glucose abolishes the inhibitory effect of glucose on SR-BI promoter activity. ${ }^{112}$ In addition, deletion of a 266-bp human SR-BI promoter sequence fragment abolishes glucose suppression of the human SR-BI promoter activity in HepG2 cells. ${ }^{112}$ SR-BI decrease due to high glucose levels has been confirmed in vitro for other cell lines. These studies also showed that PPAR $\gamma$ was upregulated, which is inconsistent with PPAR $\gamma$ effects on SR-BI and is therefore probably independent of the PPAR $\gamma$ pathway. ${ }^{91,113}$

\section{Diet}

It has been shown that an atherogenic diet comprising 2\% cholesterol and $0.5 \%$ cholate can downregulate SR-BI in a post-translational manner that does not affect mRNA levels. ${ }^{100}$ This regulation does not affect the localization of SR-BI on the hepatocyte surface. The mechanism likely involves regulation by PDZK1, which is also downregulated in parallel with SR-BI. Interestingly, only the combination of cholesterol and cholate, rather than cholesterol alone or cholate alone, resulted in significantly elevated liver cholesterol along with a decrease in hepatic SR-BI protein levels.

\section{Estrogen}

As discussed previously, SR-BI is present in steroidogenic tissues as well as in the liver. This has led to the hypothesis that estrogen may affect SR-BI regulation. In rats, high levels of synthetic estrogen can completely abolish liver SR-BI protein levels while simultaneously raising SR-BI in the adrenals and ovaries. ${ }^{18}$ It has also been shown that although estrogen downregulates SR-BI, the common alternative splice variant SR-BI.2 is upregulated in both rat livers and human HepG2 cells. ${ }^{114}$ The mechanism likely involves estrogen-binding elements in the promoter region of SR-BI. ${ }^{115}$ In addition, recent human genetic studies have shown that SR-BI polymorphisms interact with estradiol levels to affect HDL and triglyceride levels. ${ }^{116}$ The same study also showed liver SR-BI mRNA levels higher in males than in females for both SR-BI and SR-BI.2.

Overall, hepatic SR-BI is regulated by multiple independent metabolic pathways, and the majority of these pathways affect transcriptional regulation of SR-BI to control the abundance of the protein and alternative coding splice variants.

\section{Human hepatic SR-BI}

Obtaining human samples to examine hepatic SR-BI is obviously difficult and explains why there is very little direct evidence of human hepatic SR-BI function. An examination 
of 91 human liver samples showed that males have higher SR-BI mRNA than females, although this was not confirmed by protein analysis. ${ }^{116}$ Human genetic studies examining HDL cholesterol levels, and hence hepatic function of SR-BI, have examined polymorphisms in SR-BI for association in various lipid and metabolic traits. Initial analyses focused primarily on three single nucleotide polymorphism (SNPs) located in exon-1, intron-5, and exon-8. However, most of these studies showed weak association that could not be replicated. Advances in genomics have permitted significantly larger and more powerful studies to be performed, and genomewide association studies (GWAS) have now proven that SNPs in and near SR-BI are significantly associated with human plasma levels of HDL cholesterol $\left(P<3 \times 10^{-14}\right){ }^{117}$ Many of these SNPs are located downstream of the coding region, indicating that expression levels of SR-BI, likely in the liver, may be important for human HDL regulation. Interestingly, CD36 has not been associated at the genome wide level with any lipid trait, reflecting the importance of SR-BI in human HDL metabolism as the primary HDL-CE scavenger receptor.

More recently, a family with a functional mutation in SR-BI was identified through sequencing of SR-BI in a high HDL cholesterol cohort. Carriers show increased HDL cholesterol levels and reduced cholesterol efflux from macrophages but no significant increase in atherosclerosis. ${ }^{118}$ Indeed, SR-BI associations with CAD have not yet been conclusively proven, not even with GWAS associations. However, this obviously does not rule out SR-BI as a critical CAD gene. The nature of loss of function mutations in SR-BI will lead to increased HDL cholesterol, which normally provides protection against atherosclerosis. Examining HDL cholesterol levels in humans, as a marker of SR-BI functional effects on CAD, may not necessarily be the best way to prove SR-BI's CAD impact. A more direct measure of challenging patients with safe radiolabeled $\mathrm{CE}$, and determining its rate of clearance as a measure of RCT, may be a better way of determining SR-BI function. ${ }^{119}$

\section{Noncholesterol roles and considerations for hepatic SR-BI}

SR-BI is known to have functions beyond that of "HDL receptor", which may be under greater selection pressure. Indeed, the benefits of improved RCT and HDL may never have presented a selection pressure on humans, given that CAD acts after the lateral transmission of genes, and that CAD itself is a recent human disease. The evolutionary pressures that brought about and conserve SR-BI may be due to its less well-characterized functions that are beneficial for survival, such as supplying cholesterol to steroidogenic tissues for reproduction. ${ }^{51}$ More likely, however, is the increasing role that SR-BI appears to have for protection from infectious disease. We now know that SR-BI has a role in endotoxemia and innate immunity and serves as a binding site for the uptake of bacteria and clearance of plasma lipopolysaccharide (LPS) via the liver, which is primarily carried by HDL. ${ }^{120}$ SR-BI also protects against LPS-induced death and prevents nitric oxide cytotoxicity. ${ }^{121}$ In addition, SR-BI supplies cholesterol to the adrenals for synthesis of glucocorticoids (anti-inflammatory compounds), providing protection from endotoxemia. ${ }^{122}$ Serum opacity factor (SOF) is a virulence determinant protein of group A streptococci and induces opacity of mammalian serum ${ }^{123}$ because it binds to APOAI on HDL, triggering the release of the HDL lipid cargo. ${ }^{124}$ SOF converts HDL to lipid-free APOAI, neo-HDL (small HDL-like particles), and a large CE-rich microemulsion (CERM). Hepatocyte uptake of CERM-CE occurs faster than HDL-CE uptake, and CERM has a higher-affinity interaction with SR-BI compared with HDL. ${ }^{125}$ Thus, the clearance of virulence factors may have been a driving force for SR-BI evolution.

Conversely, too much SR-BI can be detrimental, as human hepatic SR-BI serves as an entry receptor for hepatitis $\mathrm{C}$ virus (HCV). ${ }^{126,127} \mathrm{HCV}$ is a RNA virus that replicates in the liver, and HCV infection is the major cause of liver fibrosis, cirrhosis, and liver cancer in the Western world, as well as the leading cause for requiring liver transplantation. ${ }^{128} \mathrm{HCV}$ infection is characterized by alterations in lipids that reflect viral dependence on host lipid metabolism for replication and assembly. ${ }^{129}$ PDZK1 can also enhance $\mathrm{HCV}$ entry via SR-BI. ${ }^{130}$ Research into developing $\mathrm{HCV}$ entry inhibitors has become a novel approach to preventing infection, and studies have identified SR-BI antagonists with potent antiviral activity. ${ }^{131}$ The antagonists are designed to target the extracellular loop of SR-BI or block SR-BI expression. ${ }^{126,132-135}$ Consequently, studies on SR-BI-directed therapies in relation to $\mathrm{HCV}$ or CVD will require overlap. For example, HCV therapies that block SR-BI expression may have long-term cardiovascular consequences.

\section{Conclusion}

Inhibiting SR-BI in mouse models increases HDL, but this increase is not healthy and results in increased atherosclerosis, either due to reduced RCT or increased APOB-containing 
lipoproteins. Overexpressing SR-BI in mouse models increases RCT, lowers APOB-containing lipoproteins, and reduces atherosclerosis, all of which serve as an optimal therapeutic package. However, increasing SR-BI without a clearer understanding of all the functions of SR-BI in humans, such as in the presence of endogenous CETP, particularly with regard to its effects on VLDL and LDL, could have detrimental effects. More research and better humanized mouse models may be required to distinguish the exact impact of human CETP, increased APOB-containing apolipoproteins and VLDL remnants, and free cholesterol flux versus reduced HDL-CE selective uptake. The consequence of raised SR-BI in the context of HCV, bacteria, LPS, and general infection and immunity could lead to an increase in bacterial infection and sepsis. ${ }^{136}$ Indeed, if SR-BI is upregulated in all tissues, including macrophages, then LPS and other inflammatory markers may promote foam cell formation and atherosclerosis.

Although SR-BI has been extensively studied in vitro and in mouse models, there are clearly many questions concerning SR-BI that require investigation, especially regarding human relevance. Now that human genetics has finally proven beyond doubt that SR-BI is correlated with human HDL cholesterol levels, we can begin to address more confidently the question of whether SR-BI is relevant for CAD. However, a better assay to assess SR-BI hepatic function and RCT in humans, rather than simply measuring HDL cholesterol, should be developed to address the direct human genetic CAD associations more robustly.

\section{Acknowledgment}

Ioannis M Stylianou is supported by the AHA Scientists Development Award 09SDG2280011.

\section{Disclosure}

The authors report no conflicts of interest in this work.

\section{References}

1. Krieger M. Charting the fate of the "good cholesterol": identification and characterization of the high-density lipoprotein receptor SR-BI. Annu Rev Biochem. 1999;68:523-558.

2. Acton S, Rigotti A, Landschulz KT, et al. Identification of scavenger receptor SR-BI as a high density lipoprotein receptor. Science. 1996; 271(5248):518-520.

3. Acton SL, Scherer PE, Lodish HF, Krieger M. Expression cloning of SR-BI, a CD36-related class B scavenger receptor. J Biol Chem. 1994; 269(33):21003-21009.

4. Vega MA, Segui-Real B, Garcia JA, et al. Cloning, sequencing, and expression of a cDNA encoding rat LIMP II, a novel 74-kDa lysosomal membrane protein related to the surface adhesion protein CD36. J Biol Chem. 1991;266(25):16818-16824.
5. Gu X, Trigatti B, Xu S, et al. The efficient cellular uptake of high density lipoprotein lipids via scavenger receptor class B type I requires not only receptor-mediated surface binding but also receptor-specific lipid transfer mediated by its extracellular domain. J Biol Chem. 1998; 273(41):26338-26348.

6. Brundert M, Heeren J, Merkel M, et al. Scavenger receptor CD36 mediates uptake of high density lipoproteins by tissues in mice and by cultured cells. J Lipid Res. January 28, 2011. [Epub ahead of print].

7. Connelly MA, Klein SM, Azhar S, et al. Comparison of class B scavenger receptors, CD36 and scavenger receptor BI (SR-BI), shows that both receptors mediate high density lipoprotein cholesteryl ester selective uptake but SR-BI exhibits a unique enhancement of cholesteryl ester uptake. J Biol Chem. 1999;274(1):41-47.

8. De Villiers WJ, Cai L, Webb NR, et al. CD36 does not play a direct role in HDL or LDL metabolism. J Lipid Res. 2001;42(8):1231-1238.

9. Sun B, Boyanovsky BB, Connelly MA, et al. Distinct mechanisms for OxLDL uptake and cellular trafficking by class B scavenger receptors CD36 and SR-BI. J Lipid Res. 2007;48(12):2560-2570.

10. Apostolov EO, Shah SV, Ray D, Basnakian AG. Scavenger receptors of endothelial cells mediate the uptake and cellular proatherogenic effects of carbamylated LDL. Arterioscler Thromb Vasc Biol. 2009; 29(10):1622-1630.

11. Abumrad NA, el-Maghrabi MR, Amri EZ, et al. Cloning of a rat adipocyte membrane protein implicated in binding or transport of long-chain fatty acids that is induced during preadipocyte differentiation. Homology with human CD36. J Biol Chem. 1993;268(24): 17665-17668.

12. Babitt J, Trigatti B, Rigotti A, et al. Murine SR-BI, a high density lipoprotein receptor that mediates selective lipid uptake, is N-glycosylated and fatty acylated and colocalizes with plasma membrane caveolae. J Biol Chem. 1997;272(20):13242-13249.

13. Fidge NH. High density lipoprotein receptors, binding proteins, and ligands. J Lipid Res. 1999;40(2):187-201.

14. Sahoo D, Peng Y, Smith JR, et al. Scavenger receptor class B, type I (SR-BI) homo-dimerizes via its C-terminal region: fluorescence resonance energy transfer analysis. Biochim Biophys Acta. 2007;1771(7): $818-829$.

15. Sahoo D, Darlington YF, Pop D, et al. Scavenger receptor class B Type I (SR-BI) assembles into detergent-sensitive dimers and tetramers. Biochim Biophys Acta. 2007;1771(7):807-817.

16. Azhar S, Nomoto A, Reaven E. Hormonal regulation of adrenal microvillar channel formation. J Lipid Res. 2002;43(6):861-871.

17. Reaven E, Cortez Y, Leers-Sucheta S, et al. Dimerization of the scavenger receptor class B type I: formation, function, and localization in diverse cells and tissues. J Lipid Res. 2004;45(3):513-528.

18. Landschulz KT, Pathak RK, Rigotti A, et al. Regulation of scavenger receptor, class $\mathrm{B}$, type $\mathrm{I}$, a high density lipoprotein receptor, in liver and steroidogenic tissues of the rat. J Clin Invest. 1996;98(4): 984-995.

19. Rodrigueza WV, Thuahnai ST, Temel RE, et al. Mechanism of scavenger receptor class B type I-mediated selective uptake of cholesteryl esters from high density lipoprotein to adrenal cells. J Biol Chem. 1999; 274(29):20344-20350.

20. Papale GA, Nicholson K, Hanson PJ, et al. Extracellular hydrophobic regions in scavenger receptor BI play a key role in mediating HDL cholesterol transport. Arch Biochem Biophys. 2010;496(2): 132-139.

21. Webb NR, de Villiers WJ, Connell PM, et al. Alternative forms of the scavenger receptor BI (SR-BI). J Lipid Res. 1997;38(7): 1490-1495.

22. Webb NR, Connell PM, Graf GA, et al. SR-BII, an isoform of the scavenger receptor $\mathrm{BI}$ containing an alternate cytoplasmic tail, mediates lipid transfer between high density lipoprotein and cells. J Biol Chem. 1998;273(24):15241-15248.

23. Eckhardt ER, Cai L, Sun B, et al. High density lipoprotein uptake by scavenger receptor SR-BII. J Biol Chem. 2004;279(14):14372-14381. 
24. Eckhardt ER, Cai L, Shetty S, et al. High density lipoprotein endocytosis by scavenger receptor SR-BII is clathrin-dependent and requires a carboxyl-terminal dileucine motif. J Biol Chem. 2006; 281(7):4348-4353.

25. Nakagawa-Toyama Y, Hirano K, Tsujii K, et al. Human scavenger receptor class B type I is expressed with cell-specific fashion in both initial and terminal site of reverse cholesterol transport. Atherosclerosis. 2005; 183(1):75-83.

26. Kozarsky KF, Donahee MH, Rigotti A, et al. Overexpression of the HDL receptor SR-BI alters plasma HDL and bile cholesterol levels. Nature. 1997;387(6631):414-417.

27. Ikemoto M, Arai H, Feng D, et al. Identification of a PDZ-domaincontaining protein that interacts with the scavenger receptor class B type I. Proc Natl Acad Sci U S A. 2000;97(12):6538-6543.

28. Silver DL, Wang N, Xiao X, Tall AR. High density lipoprotein (HDL) particle uptake mediated by scavenger receptor class B type 1 results in selective sorting of HDL cholesterol from protein and polarized cholesterol secretion. J Biol Chem. 2001;276(27):25287-25293.

29. Stangl H, Graf GA, Yu L, et al. Effect of estrogen on scavenger receptor BI expression in the rat. $J$ Endocrinol. 2002;175(3):663-672.

30. Sehayek E, Wang R, Ono JG, et al. Localization of the PE methylation pathway and SR-BI to the canalicular membrane: evidence for apical PC biosynthesis that may promote biliary excretion of phospholipid and cholesterol. J Lipid Res. 2003;44(9):1605-1613.

31. Harder CJ, Meng A, Rippstein P, et al. SR-BI undergoes cholesterolstimulated transcytosis to the bile canaliculus in polarized WIF-B cells. J Biol Chem. 2007;282(2):1445-1455.

32. Graf GA, Connell PM, van der Westhuyzen DR, Smart EJ. The class B, type I scavenger receptor promotes the selective uptake of high density lipoprotein cholesterol ethers into caveolae. J Biol Chem. 1999; 274(17):12043-12048.

33. Rothberg KG, Heuser JE, Donzell WC, et al. Caveolin, a protein component of caveolae membrane coats. Cell. 1992;68(4):673-682.

34. Fielding PE, Fielding CJ. Plasma membrane caveolae mediate the efflux of cellular free cholesterol. Biochemistry. 1995;34(44):14288-14292.

35. Reaven E, Spicher M, Azhar S. Microvillar channels: a unique plasma membrane compartment for concentrating lipoproteins on the surface of rat adrenal cortical cells. J Lipid Res. 1989;30(10):1551-1560.

36. Reaven E, Nomoto A, Leers-Sucheta S, et al. Expression and microvillar localization of scavenger receptor, class B, type I (a high density lipoprotein receptor) in luteinized and hormone-desensitized rat ovarian models. Endocrinology. 1998;139(6):2847-2856.

37. Williams DL, Wong JS, Hamilton RL. SR-BI is required for microvillar channel formation and the localization of HDL particles to the surface of adrenocortical cells in vivo. J Lipid Res. 2002;43(4):544-549.

38. Peng Y, Akmentin W, Connelly MA, et al. Scavenger receptor BI (SR-BI) clustered on microvillar extensions suggests that this plasma membrane domain is a way station for cholesterol trafficking between cells and high-density lipoprotein. Mol Biol Cell. 2004;15(1):384-396.

39. Wang LB, Connelly MA, Ostermeyer AG, et al. Caveolin-1 does not affect SR-BI-mediated cholesterol efflux or selective uptake of cholesteryl ester in two cell lines. J Lipid Res. 2003;44(4):807-815.

40. Li WP, Liu P, Pilcher BK, Anderson RG. Cell-specific targeting of caveolin-1 to caveolae, secretory vesicles, cytoplasm or mitochondria. J Cell Sci. 2001;114(7):1397-1408.

41. Truong TQ, Aubin D, Bourgeois P, et al. Opposite effect of caveolin-1 in the metabolism of high-density and low-density lipoproteins. Biochim Biophys Acta. 2006;1761(1):24-36.

42. Ritsch A, Tancevski I, Schgoer W, et al. Molecular characterization of rabbit scavenger receptor class B types I and II: portal to central vein gradient of expression in the liver. $J$ Lipid Res. 2004;45(2): 214-222.

43. Spady DK, Kearney DM, Hobbs HH. Polyunsaturated fatty acids up-regulate hepatic scavenger receptor B1 (SR-BI) expression and HDL cholesteryl ester uptake in the hamster. J Lipid Res. 1999; 40(8):1384-1394.
44. Rigotti A, Trigatti BL, Penman M, et al. A targeted mutation in the murine gene encoding the high density lipoprotein (HDL) receptor scavenger receptor class B type I reveals its key role in HDL metabolism. Proc Natl Acad Sci U SA. 1997;94(23):12610-12615.

45. Kozarsky KF, Donahee MH, Glick JM, et al. Gene transfer and hepatic overexpression of the HDL receptor SR-BI reduces atherosclerosis in the cholesterol-fed LDL receptor-deficient mouse. Arterioscler Thromb Vasc Biol. 2000;20(3):721-727.

46. Wang N, Arai T, Ji Y, et al. Liver-specific overexpression of scavenger receptor BI decreases levels of very low density lipoprotein ApoB, low density lipoprotein $\mathrm{ApoB}$, and high density lipoprotein in transgenic mice. J Biol Chem. 1998;273(49):32920-32926.

47. Ueda Y, Royer L, Gong E, et al. Lower plasma levels and accelerated clearance of high density lipoprotein (HDL) and non-HDL cholesterol in scavenger receptor class B type I transgenic mice. J Biol Chem. 1999; 274(11):7165-7171.

48. Arai T, Rinninger F, Varban L, et al. Decreased selective uptake of high density lipoprotein cholesteryl esters in apolipoprotein E knock-out mice. Proc Natl Acad Sci U S A. 1999;96(21):12050-12055.

49. Ueda Y, Gong E, Royer L, et al. Relationship between expression levels and atherogenesis in scavenger receptor class B, type I transgenics. J Biol Chem. 2000;275(27):20368-20373.

50. Van Eck M, Twisk J, Hoekstra M, et al. Differential effects of scavenger receptor BI deficiency on lipid metabolism in cells of the arterial wall and in the liver. J Biol Chem. 2003;278(26):23699-23705.

51. Trigatti B, Rayburn H, Vinals M, et al. Influence of the high density lipoprotein receptor SR-BI on reproductive and cardiovascular pathophysiology. Proc Natl Acad Sci U S A. 1999;96(16): 9322-9327.

52. Braun A, Trigatti BL, Post MJ, et al. Loss of SR-BI expression leads to the early onset of occlusive atherosclerotic coronary artery disease, spontaneous myocardial infarctions, severe cardiac dysfunction, and premature death in apolipoprotein E-deficient mice. Circ Res. 2002; 90(3):270-276.

53. Varban ML, Rinninger F, Wang N, et al. Targeted mutation reveals a central role for SR-BI in hepatic selective uptake of high density lipoprotein cholesterol. Proc Natl Acad Sci U S A. 1998;95(8): 4619-4624.

54. Huszar D, Varban ML, Rinninger F, et al. Increased LDL cholesterol and atherosclerosis in LDL receptor-deficient mice with attenuated expression of scavenger receptor B1. Arterioscler Thromb Vasc Biol. 2000;20(4):1068-1073.

55. Huby T, Doucet C, Dachet C, et al. Knockdown expression and hepatic deficiency reveal an atheroprotective role for SR-BI in liver and peripheral tissues. J Clin Invest. 2006;116(10):2767-2776.

56. Wang X, Collins HL, Ranalletta M, et al. Macrophage ABCA1 and ABCG1, but not SR-BI, promote macrophage reverse cholesterol transport in vivo. J Clin Invest. 2007;117(8):2216-2224.

57. Stylianou IM, Svenson KL, VanOrman SK, et al. Novel ENU-induced point mutation in scavenger receptor class $\mathrm{B}$, member 1 , results in liver specific loss of SCARB1 protein. PLoS One. 2009;4(8):e6521.

58. Out R, Hoekstra M, de Jager SC, et al. Adenovirus-mediated hepatic overexpression of scavenger receptor class B type I accelerates chylomicron metabolism in C57BL/6J mice. J Lipid Res. 2005;46(6):1172-1181.

59. Kathiresan S, Willer CJ, Peloso GM, et al. Common variants at 30 loci contribute to polygenic dyslipidemia. Nat Genet. 2009;41(1): $56-65$.

60. Harder C, Lau P, Meng A, et al. Cholesteryl ester transfer protein (CETP) expression protects against diet induced atherosclerosis in SR-BI deficient mice. Arterioscler Thromb Vasc Biol. 2007;27(4): 858-864.

61. Zhou H, Li Z, Silver DL, Jiang XC. Cholesteryl ester transfer protein (CETP) expression enhances HDL cholesteryl ester liver delivery, which is independent of scavenger receptor BI, LDL receptor related protein and possibly LDL receptor. Biochim Biophys Acta. 2006; 1761(12):1482-1488. 
62. Jiang XC, Agellon LB, Walsh A, et al. Dietary cholesterol increases transcription of the human cholesteryl ester transfer protein gene in transgenic mice. Dependence on natural flanking sequences. J Clin Invest. 1992;90(4):1290-1295.

63. Hildebrand RB, Lammers B, Meurs I, et al. Restoration of high-density lipoprotein levels by cholesteryl ester transfer protein expression in scavenger receptor class B type I (SR-BI) knockout mice does not normalize pathologies associated with SR-BI deficiency. Arterioscler Thromb Vasc Biol. 2010;30(7):1439-1445.

64. Out R, Kruijt JK, Rensen PC, et al. Scavenger receptor BI plays a role in facilitating chylomicron metabolism. J Biol Chem. 2004;279(18): 18401-18406.

65. Wiersma H, Nijstad N, Gautier T, et al. Scavenger receptor BI facilitates hepatic very low density lipoprotein production in mice. J Lipid Res. 2010;51(3):544-553.

66. Calvo D, Gomez-Coronado D, Lasuncion MA, Vega MA. CLA-1 is an $85-\mathrm{kD}$ plasma membrane glycoprotein that acts as a high-affinity receptor for both native (HDL, LDL, and VLDL) and modified (OxLDL and AcLDL) lipoproteins. Arterioscler Thromb Vasc Biol. 1997; 17(11):2341-2349.

67. Van Eck M, Hoekstra M, Out R, et al. Scavenger receptor BI facilitates the metabolism of VLDL lipoproteins in vivo. J Lipid Res. 2008;49(1): 136-146.

68. Glomset JA. The plasma lecithins:cholesterol acyltransferase reaction J Lipid Res. 1968;9(2):155-167.

69. Tall AR. Cholesterol efflux pathways and other potential mechanisms involved in the athero-protective effect of high density lipoproteins. J Intern Med. 2008;263(3):256-273.

70. Berge KE, Tian H, Graf GA, et al. Accumulation of dietary cholesterol in sitosterolemia caused by mutations in adjacent ABC transporters. Science. 2000;290(5497):1771-1775.

71. Zhang Y, Zanotti I, Reilly MP, et al. Overexpression of apolipoprotein A-I promotes reverse transport of cholesterol from macrophages to feces in vivo. Circulation. 2003;108(6):661-663.

72. Brundert M, Heeren J, Bahar-Bayansar M, et al. Selective uptake of HDL cholesteryl esters and cholesterol efflux from mouse peritoneal macrophages independent of SR-BI. J Lipid Res. 2006;47(11):2408-2421.

73. Adorni MP, Zimetti F, Billheimer JT, et al. The roles of different pathways in the release of cholesterol from macrophages. J Lipid Res. 2007;48(11):2453-2462.

74. Covey SD, Krieger M, Wang W, et al. Scavenger receptor class B type I-mediated protection against atherosclerosis in LDL receptor-negative mice involves its expression in bone marrow-derived cells. Arterioscler Thromb Vasc Biol. 2003;23(9):1589-1594.

75. Van Eck M, Bos IS, Hildebrand RB, et al. Dual role for scavenger receptor class $\mathrm{B}$, type $\mathrm{I}$ on bone marrow-derived cells in atherosclerotic lesion development. Am J Pathol. 2004;165(3):785-794.

76. Zhao Y, Pennings M, Hildebrand RB, et al. Enhanced foam cell formation, atherosclerotic lesion development, and inflammation by combined deletion of ABCA1 and SR-BI in bone marrow-derived cells in LDL receptor knockout mice on Western-type diet. Circ Res. 2010; 107:e20-e31

77. Yancey PG, de la Llera-Moya M, Swarnakar S, et al. High density lipoprotein phospholipid composition is a major determinant of the bidirectional flux and net movement of cellular free cholesterol mediated by scavenger receptor BI. J Biol Chem. 2000;275(47):36596-36604.

78. Ji Y, Jian B, Wang N, et al. Scavenger receptor BI promotes high density lipoprotein-mediated cellular cholesterol efflux. J Biol Chem. 1997;272(34):20982-20985.

79. Zhang Y, Da Silva JR, Reilly M, et al. Hepatic expression of scavenger receptor class $\mathrm{B}$ type $\mathrm{I}(\mathrm{SR}-\mathrm{BI})$ is a positive regulator of macrophage reverse cholesterol transport in vivo. J Clin Invest. 2005;115(10): 2870-2874.

80. Silver DL. A carboxyl-terminal PDZ-interacting domain of scavenger receptor $\mathrm{B}$, type I is essential for cell surface expression in liver. J Biol Chem. 2002;277(37):34042-34047.
81. Silver DL, Wang N, Vogel S. Identification of small PDZK1-associated protein, DD96/MAP17, as a regulator of PDZK1 and plasma high density lipoprotein levels. J Biol Chem. 2003;278(31):28528-28532.

82. Tachibana K, Anzai N, Ueda C, et al. Regulation of the human PDZK1 expression by peroxisome proliferator-activated receptor alpha. FEBS Lett. 2008;582(28):3884-3888.

83. Kocher O, Yesilaltay A, Cirovic C, et al. Targeted disruption of the PDZK1 gene in mice causes tissue-specific depletion of the high density lipoprotein receptor scavenger receptor class B type I and altered lipoprotein metabolism. J Biol Chem. 2003;278(52):52820-52825.

84. Kocher O, Yesilaltay A, Shen $\mathrm{CH}$, et al. Influence of PDZK1 on lipoprotein metabolism and atherosclerosis. Biochim Biophys Acta. 2008;1782(5):310-316.

85. Yesilaltay A, Daniels K, Pal R, et al. Loss of PDZK1 causes coronary artery occlusion and myocardial infarction in Paigen diet-fed apolipoprotein E deficient mice. PLoS One. 2009;4(12):e8103.

86. Chao F, Gong W, Zheng Y, et al. Upregulation of scavenger receptor class B type I expression by activation of FXR in hepatocyte. Atherosclerosis. 2010;213(2):443-448.

87. Lambert G, Amar MJ, Guo G, et al. The farnesoid X-receptor is an essential regulator of cholesterol homeostasis. J Biol Chem. 2003; 278(4):2563-2570

88. Chiang JY. Bile acid regulation of gene expression: roles of nuclear hormone receptors. Endocr Rev. 2002;23(4):443-463.

89. Pineda Torra I, Claudel T, Duval C, et al. Bile acids induce the expression of the human peroxisome proliferator-activated receptor alpha gene via activation of the farnesoid X receptor. Mol Endocrinol. 2003;17(2):259-272.

90. Fiorucci S, Rizzo G, Antonelli E, et al. Cross-talk between farnesoid-X-receptor (FXR) and peroxisome proliferator-activated receptor gamma contributes to the antifibrotic activity of FXR ligands in rodent models of liver cirrhosis. J Pharmacol Exp Ther. 2005;315(1):58-68.

91. Ahmed RA, Murao K, Imachi H, et al. Human scavenger receptor class $\mathrm{B}$ type 1 is regulated by activators of peroxisome proliferators-activated receptor-gamma in hepatocytes. Endocrine. 2009;35(2):233-242.

92. Sinal CJ, Tohkin M, Miyata M, et al. Targeted disruption of the nuclear receptor FXR/BAR impairs bile acid and lipid homeostasis. Cell. 2000; 102(6):731-744.

93. Zhang Y, Wang X, Vales C, et al. FXR deficiency causes reduced atherosclerosis in Ldlr-/- mice. Arterioscler Thromb Vasc Biol. 2006; 26(10):2316-2321.

94. Edwards PA, Kast HR, Anisfeld AM. BAREing it all: the adoption of LXR and FXR and their roles in lipid homeostasis. J Lipid Res. 2002; 43(1):2-12.

95. Kalaany NY, Mangelsdorf DJ. LXRS and FXR: the yin and yang of cholesterol and fat metabolism. Annu Rev Physiol. 2006;68:159-191.

96. Malerod L, Juvet LK, Hanssen-Bauer A, et al. Oxysterol-activated LXRalpha/RXR induces hSR-BI-promoter activity in hepatoma cells and preadipocytes. Biochem Biophys Res Commun. 2002;299(5):916-923.

97. Bradley MN, Hong C, Chen M, et al. Ligand activation of LXR beta reverses atherosclerosis and cellular cholesterol overload in mice lacking LXR alpha and apoE. J Clin Invest. 2007;117(8):2337-2346.

98. Tangirala RK, Bischoff ED, Joseph SB, et al. Identification of macrophage liver X receptors as inhibitors of atherosclerosis. Proc Natl Acad Sci U S A. 2002;99(18):11896-11901.

99. Shimano H, Horton JD, Hammer RE, et al. Overproduction of cholesterol and fatty acids causes massive liver enlargement in transgenic mice expressing truncated SREBP-1a. J Clin Invest. 1996;98(7):1575-1584.

100. Niemeier A, Kovacs WJ, Strobl W, Stangl H. Atherogenic diet leads to posttranslational down-regulation of murine hepatocyte SR-BI expression. Atherosclerosis. 2009;202(1):169-175.

101. Watts GF, Dimmitt SB. Fibrates, dyslipoproteinaemia and cardiovascular disease. Curr Opin Lipidol. 1999;10(6):561-574.

102. Mellies MJ, Stein EA, Khoury P, et al. Effects of fenofibrate on lipids, lipoproteins, and apolipoproteins in 33 subjects with primary hypercholesterolemia. Atherosclerosis. 1987;63(1):57-64. 
103. Staels B, Dallongeville J, Auwerx J, et al. Mechanism of action of fibrates on lipid and lipoprotein metabolism. Circulation. 1998; 98(19):2088-2093.

104. Schoonjans K, Staels B, Auwerx J. Role of the peroxisome proliferatoractivated receptor (PPAR) in mediating the effects of fibrates and fatty acids on gene expression. J Lipid Res. 1996;37(5):907-925.

105. Schoonjans K, Staels B, Auwerx J. The peroxisome proliferator activated receptors (PPARS) and their effects on lipid metabolism and adipocyte differentiation. Biochim Biophys Acta. 1996;1302(2):93-109.

106. Mardones P, Pilon A, Bouly M, et al. Fibrates down-regulate hepatic scavenger receptor class B type I protein expression in mice. $J$ Biol Chem. 2003;278(10):7884-7890.

107. Lan D, Silver DL. Fenofibrate induces a novel degradation pathway for scavenger receptor B-I independent of PDZK1. J Biol Chem. 2005; 280(24):23390-23396.

108. Nieland TJ, Shaw JT, Jaipuri FA, et al. Influence of HDL cholesterolelevating drugs on the in vitro activity of the HDL receptor SR-BI. J Lipid Res. 2007;48(8):1832-1845.

109. Forcheron F, Cachefo A, Thevenon S, et al. Mechanisms of the triglyceride- and cholesterol-lowering effect of fenofibrate in hyperlipidemic type 2 diabetic patients. Diabetes. 2002;51(12):3486-3491.

110. Pyorala K, Laakso M, Uusitupa M. Diabetes and atherosclerosis: an epidemiologic view. Diabetes Metab Rev. 1987;3(2):463-524.

111. Haffner SM, Lehto S, Ronnemaa T, et al. Mortality from coronary heart disease in subjects with type 2 diabetes and in nondiabetic subjects with and without prior myocardial infarction. $N$ Engl J Med. 1998; 339(4):229-234.

112. Murao K, Yu X, Imachi H, et al. Hyperglycemia suppresses hepatic scavenger receptor class B type I expression. Am J Physiol Endocrinol Metab. 2008;294(1):E78-E87.

113. Ravid Z, Bendayan M, Delvin E, et al. Modulation of intestinal cholesterol absorption by high glucose levels: impact on cholesterol transporters, regulatory enzymes, and transcription factors. Am J Physiol Gastrointest Liver Physiol. 2008;295(5):G873-G885.

114. Graf GA, Roswell KL, Smart EJ. 17beta-estradiol promotes the up-regulation of SR-BII in HepG2 cells and in rat livers. J Lipid Res. 2001;42(9):1444-1449.

115. Lopez D, Sanchez MD, Shea-Eaton W, McLean MP. Estrogen activates the high-density lipoprotein receptor gene via binding to estrogen response elements and interaction with sterol regulatory element binding protein-1A. Endocrinology. 2002;143(6):2155-2168.

116. Chiba-Falek O, Nichols M, Suchindran S, et al. Impact of gene variants on sex-specific regulation of human scavenger receptor class B type 1 (SR-BI) expression in liver and association with lipid levels in a population-based study. BMC Med Genet. 2010;11:9.

117. Teslovich TM, Musunuru K, Smith AV, et al. Biological, clinical and population relevance of 95 loci for blood lipids. Nature. 2010; 466(7307):707-713.

118. Vergeer M, Korporaal SJ, Franssen R, et al. Genetic variant of the scavenger receptor BI in humans. N Engl J Med. 2011;364(2):136-145.

119. Holleboom AG, Franssen R, Jakulj L, et al. Abstract 17881: in vivo tissue cholesterol efflux is impaired in carriers of mutations in APOA1 and ABCA1. Circulation. 2010(21 Supplement Abstracts From Scientific Sessions 2010):Abstract 17881.

120. Wurfel MM, Kunitake ST, Lichenstein H, et al. Lipopolysaccharide (LPS)-binding protein is carried on lipoproteins and acts as a cofactor in the neutralization of LPS. J Exp Med. 1994;180(3):1025-1035.

Hepatic Medicine: Evidence and Research

\section{Publish your work in this journal}

Hepatic Medicine: Evidence and Research is an international, peerreviewed, open access journal covering all aspects of adult and pediatric hepatology in the clinic and laboratory including the following topics: Pathology, pathophysiology of hepatic disease; Investigation and treatment of hepatic disease; Pharmacology of drugs used for
121. Li XA, Guo L, Asmis R, et al. Scavenger receptor BI prevents nitric oxide-induced cytotoxicity and endotoxin-induced death. Circ Res. 2006;98(7):e60-e65.

122. Cai L, Ji A, de Beer FC, et al. SR-BI protects against endotoxemia in mice through its roles in glucocorticoid production and hepatic clearance. J Clin Invest. 2008;118(1):364-375.

123. Hallas G, Widdowson JP. The opacity factor of group-A streptococci. J Med Microbiol. 1982;15(4):451-464.

124. Courtney HS, Zhang YM, Frank MW, Rock CO. Serum opacity factor, a streptococcal virulence factor that binds to apolipoproteins A-I and A-II and disrupts high density lipoprotein structure. J Biol Chem. 2006;281(9):5515-5521.

125. Gillard BK, Rosales C, Pillai BK, et al. Streptococcal serum opacity factor increases the rate of hepatocyte uptake of human plasma high-density lipoprotein cholesterol. Biochemistry. 2010;49(45):9866-9873.

126. Kapadia SB, Barth H, Baumert T, et al. Initiation of hepatitis $\mathrm{C}$ virus infection is dependent on cholesterol and cooperativity between CD81 and scavenger receptor B type I. J Virol. 2007;81(1):374-383.

127. Scarselli E, Ansuini H, Cerino R, et al. The human scavenger receptor class $\mathrm{B}$ type $\mathrm{I}$ is a novel candidate receptor for the hepatitis $\mathrm{C}$ virus. EMBO J. 2002;21(19):5017-5025.

128. Shepard CW, Finelli L, Alter MJ. Global epidemiology of hepatitis C virus infection. Lancet Infect Dis. 2005;5(9):558-567.

129. Burlone ME, Budkowska A. Hepatitis C virus cell entry: role of lipoproteins and cellular receptors. J Gen Virol. 2009;90(5): 1055-1070.

130. Eyre NS, Drummer HE, Beard MR. The SR-BI partner PDZK1 facilitates hepatitis C virus entry. PLoS Pathog. 2010;6(10): e1001130.

131. Syder AJ, Lee H, Zeisel MB, et al. Small molecule scavenger receptor BI antagonists are potent HCV entry inhibitors. J Hepatol. 2011; 54(1):48-55.

132. Catanese MT, Graziani R, von Hahn T, et al. High-avidity monoclonal antibodies against the human scavenger class B type I receptor efficiently block hepatitis $\mathrm{C}$ virus infection in the presence of high-density lipoprotein. J Virol. 2007;81(15):8063-8071.

133. Grove J, Huby T, Stamataki Z, et al. Scavenger receptor BI and BII expression levels modulate hepatitis C virus infectivity. JVirol. 2007; 81(7):3162-3169.

134. Bartosch B, Vitelli A, Granier C, et al. Cell entry of hepatitis C virus requires a set of co-receptors that include the CD81 tetraspanin and the SR-B1 scavenger receptor. J Biol Chem. 2003;278(43): 41624-41630.

135. Lavillette D, Tarr AW, Voisset C, et al. Characterization of host-range and cell entry properties of the major genotypes and subtypes of hepatitis C virus. Hepatology. 2005;41(2):265-274.

136. Vishnyakova TG, Kurlander R, Bocharov AV, et al. CLA-1 and its splicing variant CLA-2 mediate bacterial adhesion and cytosolic bacterial invasion in mammalian cells. Proc Natl Acad Sci U S A. 2006; 103(45):16888-16893.

137. Webb NR, de Beer MC, Yu J, et al. Overexpression of SR-BI by adenoviral vector promotes clearance of apoA-I, but not apoB, in human apoB transgenic mice. J Lipid Res. 2002;43(9):1421-1428.

138. Zhang W, Yancey PG, Su YR, et al. Inactivation of macrophage scavenger receptor class B type I promotes atherosclerotic lesion development in apolipoprotein E-deficient mice. Circulation. 2003; 108(18):2258-2263.

\section{Dovepress}

the treatment of hepatic disease. Issues of patient safety and quality of care will also be considered. The manuscript management system is completely online and includes a very quick and fair peer-review system, which is all easy to use. Visit http://www.dovepress.com/ testimonials.php to read real quotes from published authors. 